\title{
PÓS-POSITIVISMO JURÍDICO E NORMA JURÍDICA: UMA ANÁLISE SOBRE A LEGITIMAÇÃO JUDICIAL NO PROCESSO CONSTRUTIVO DO DIREITO
}

SUMÁRIO: Introdução; 1.1 O pós-positivismo como superação do juspositivismo clássico; 2 a inserção da teoria estruturante da norma de Friedrich Müller no pós-positivismo jurídico; 3 As etapas do processo decisório no Estado de direito democrático a partir da metódica jurídica estruturante; 4 A legitimidade da atuação jurisdicional na criação da norma jurídica no Estado democrático de Direito; 5 Considerações finais; Referências.

RESUMO: O presente artigo propõe analisar os aspectos relativos à legitimação judicial no processo de construção da norma jurídica diante do caso concreto, no paradigma do pós-positivismo jurídico. $O$ processo de criação da norma jurídica em abstrato pertence, no sistema de separação dos poderes, ao Poder Legislativo, composto por membros eleitos diretamente pelo povo. O Poder Judiciário, enquanto um dos poderes da República, é composto por membros não eleitos pelo povo, o que permite a discussão acerca da legitimação judicial das decisões que criam a norma jurídica aplicável ao caso concreto. Nesse sentido, apresenta-se o presente artigo científico que buscará investigar os requisitos necessários para a validação da atividade criativa do direito pelos órgãos do Poder Judiciário diante do caso concreto, à luz da teoria estruturante da norma desenvolvida por Friedrich Müller.

PALAVRAS-CHAVE: Pós-positivismo; Legitimidade; Poder Judiciário.

\section{POST-POSITIVE AND THE LEGAL NORM: THE LEGAL LEGITIMATION IN THE CONSTRUCTIVE PROCESS OF LAW}

ABSTRACT: the present article proposes to analyze the aspects related to judicial legitimation in the process of construction of the legal norm in the concrete case, in the paradigm of legal post-positivism. The process of creating the legal norm in abstract belongs, in the system of separation of powers, to the Legislature, composed of members directly elected by the people. The Judiciary, while one of the powers of the Republic, is composed of members not elected by the people, which allows the

Doutorando em Direito do Trabalho pela Pontifícia Universidade Católica de São Paulo. Mestre em Direitos e Garantias Fundamentais pela Faculdade de Direito de Vitória. Juiz do Trabalho Substituto no Tribunal Regional do Trabalho da 17 Região, Brasil. E-mail: faustogaia@yahoo.com.br 
discussion about the judicial legitimation of the decisions that create the legal norm applicable to the concrete case. In this sense, we present the present scientific article that will investigate the necessary requirements for the validation of the creative activity of the right by the organs of the Judiciary Power in the concrete case, in light of the structuring theory of the norm developed by Friedrich Müller.

KEY WORDS: Post-positivism; Legitimation; Judiciary Power.

\section{POST-POSITIVISMO JURÍDICO Y NORMA JURÍDICA: UN ANÁLISIS SOBRE LA LEGITIMACIÓN JUDICIAL EN EL PROCESO CONSTRUCTIVO DEL DERECHO}

RESUMEN: en el presente artículo se propone analizar los aspectos relativos a la legitimación judicial en el proceso de construcción de la norma jurídica delante del caso concreto, en el paradigma del post-positivismo jurídico. El proceso de creación de la norma jurídica en abstracto pertenece, en el sistema de separación de los poderes, al Poder Legislativo, compuesto por miembros electos directamente por el pueblo. El Poder Judiciario, como uno de los poderes de la República, está compuesto por miembros no electos por el pueblo, lo que permite la discusión acerca de la legitimación judicial de las decisiones que crean la norma jurídica aplicable al caso concreto. En ese sentido, se presenta el presente artículo científico que buscará investigar los requisitos necesarios para la validación de la actividad creativa del derecho por los órganos del Poder Judiciario delante del caso concreto, a la luz de la teoría estructurante de la norma desarrollada por Friedrich Müller.

PALABRAS CLAVE: Post-positivismo; Legitimidad; Poder Judiciario.

\section{INTRODUÇÃO}

O princípio da separação dos poderes tem como pressuposto de existência o sistema constitucional rígido de fixação de competências. A Constituição Federal de 1988, seguindo os modelos ocidentais de tradição constitucional democrática, reconheceu os poderes Executivo, Legislativo e Judiciário como independentes e harmônicos entre si, dentro de um sistema de pesos e contrapesos.

Os poderes Executivo e Legislativo são compostos por membros eleitos diretamente pelo povo, por meio de sistema de votação livre e periódica. A legitimação 
da atuação desses poderes decorre do próprio mandato outorgado pelo povo no sistema eleitoral, de quem todo o poder emana.

A atividade jurisdicional, por sua vez, difere quanto à legitimidade dos demais poderes da República, seja porque seus membros não são escolhidos pelo povo por meio de sistema de eleição livre, seja também pelo fato de que a investidura do cargo se dá de forma vitalícia, após o cumprimento do estágio probatório de vitaliciedade de dois anos para os órgãos jurisdicionais de primeiro grau.

Não obstante essas diferenças na forma de provimento e de permanência no cargo, não se pode negar que a Constituição Federal confere aos órgãos judicantes a legitimidade necessária para que as decisões proferidas sejam cumpridas.

A legitimação da atuação do Poder Judiciário decorre de diversas garantias conferidas pelo texto constitucional no Estado democrático de Direito, como a necessidade de motivação das decisões judiciais, a observância do devido processo legal, o direito ao contraditório e à ampla defesa, o duplo grau de jurisdição, a possibilidade da produção da prova, a publicidade dos julgamentos, dentre outras tantas elencadas ao longo da Constituição Federal de 1988.

O paradigma do pós-positivismo jurídico, que tem a centralidade da Constituição e a força normativa dos princípios constitucionais como seus eixos centrais, permitiu o desenvolvimento da teoria de que a criação da norma jurídica somente é possível diante das particularidades do caso concreto.

O papel do Poder Legislativo é precipuamente o de elaborar, em caráter geral e abstrato, textos de normas jurídicas que serão observadas pelos órgãos jurisdicionais em suas decisões.

Diante da fixação da competência legislativa privativa ao Poder Legislativo, questiona-se se a atividade criativa da norma jurídica a partir do texto da norma pelo Poder Judiciário implicaria a existência de violação ao princípio da separação dos poderes, bem como se haveria falta de legitimação social esse processo criativo?

Em um cenário do dialeticismo material, partirá da tese de que a atividade jurisdicional está adstrita aos contornos estabelecidos pelo Poder Legislativo na confecção do texto legal. Como negação a essa ideia central, partirá da compreensão de que a liberdade, conferida em um Estado democrático de Direito, permite aos órgãos do Poder Judiciário construir livremente as normas jurídicas a serem aplicáveis ao caso concreto.

A partir do discurso dialético, permitirá investigar em síntese se, a partir da teoria estruturante da norma, desenvolvida por Friedrich Müller, é possível conferir 
legitimidade e validade à atividade criativa da norma jurídica no caso concreto por parte do Poder Judiciário.

\subsection{O PÓS-POSITIVISMO COMO SUPERAÇÃO DO JUSPOSITIVISMO CLÁSSICO}

O juspositivismo clássico demonstrou inúmeras dificuldades ante a complexidade da sociedade do pós-guerra, em que as discussões jurídicas travadas são caracterizadas pelo elemento massificador dos conflitos e também pela natureza metaindividual dos direitos violados.

A divisão entre as esferas do "ser" e do "dever-ser", entre o direito positivado e as normas de ordem moral e a confiança de que o silogismo na aplicação da norma jurídica ensejaria a segurança jurídica necessária ao ordenamento jurídico, mostraram sua ineficácia para pacificar os conflitos existentes na sociedade global, principalmente se levar em consideração o sistema de elaboração das normas jurídicas observado desde o modelo do Estado liberal e que de certo modo se manteve até o advento do Estado democrático de Direito, passando pelo Estado social de Direito.

O processo de elaboração das normas jurídicas no positivismo jurídico tem o objetivo de regular, sem lacunas, a inteireza das relações individuais em sentido amplo, donde se inserem aquelas existentes entre o Poder Público e os particulares, secundarizando a outro nível a regulamentação de conflitos de natureza metaindividual ou coletiva.

A interpretação no modelo do positivismo jurídico é marcada pela ausência de valoração na atividade hermenêutica, assentada em elementos filológicos da língua e da completude do sistema jurídico, por meio das interpretações gramatical e sistemática. Esse modelo interpretativo do direito positivado colocou em um segundo plano de importância temas como a justiça e a legitimidade das decisóes judiciais ${ }^{02}$, em razão da compreensão de identidade entre o conteúdo do texto de lei e da norma jurídica em si e da pretensão formalista pura do direito, despida de elementos de ordem moral.

A compreensão da existência de justiça e de legitimidade da decisão judicial na perspectiva do juspositivismo era apenas possível pela aplicação, por parte do intérprete autêntico, do direito objetivo elaborado pelo órgão produtor normativo.

O alcance da norma jurídica, concebida com o escopo de solucionar con-

${ }^{02}$ KIM, Richard Pae. Neoconstitucionalismo: hermenêutica constitucional e atividade jurisdicional na tutela dos direitos do cidadão. Revista da Ajuris, Porto Alegre, ano XXXVI, n. 116, p. 275, dez. 2009. 
flitos individuais, em um primeiro momento, implicou para o aplicador do direito inúmeras limitações na solução dos casos concretos, uma vez que o texto normativo tinha a pretensão, em razão do escopo de segurança jurídica do Estado liberal, de trazer a resposta do conflito, por meio da aplicação silogística do direito positivado.

A inclusão em campo secundário dos elementos da facticidade no processo hermenêutico do positivismo jurídico ensejou o questionamento acerca da fragilização do elemento justiça da decisão, em nome de uma teoria pura de interpretação do direito positivado.

Reinhold Zippelius destaca que o direito e a realidade compõem as duas faces de uma mesma moeda, assumindo uma relação de reciprocidade, de influência e de mútua dependência. Destaca, outrossim, que as normas jurídicas revelam seus conteúdos por "factos antropológicos e por fatores sociais, particularmente por necessidades e correlações de forças, bem como por outras circunstâncias, mas sobretudo pelos interesses que o direito deve regular" ${ }^{\prime 3}$.

$\mathrm{O}$ ponto de ponderação e de crítica que recebeu o positivismo jurídico nesse ponto está no distanciamento ideológico entre o ordenamento jurídico e a facticidade, a partir da negação da influência que os elementos sociais exercem sobre o conteúdo da norma jurídica. Os elementos da facticidade no juspositivismo assumem caráter secundário, muitas vezes associados a uma reflexão sociológica ou histórica independente para a ciência jurídica ${ }^{04}$.

O positivismo jurídico é assentado na premissa de que o conteúdo da norma jurídica, o que inclui a valoração dos elementos sociais, é elaborado pelos órgãos legislativos no processo de construção do texto normativo, especialmente durante o processo de discussão entre os representantes do povo. A realização da valoração e da escolha dos fatos sociais que serão regulados pelo direito é feita aprioristicamente, ou seja, antes da própria ocorrência do fato jurídico.

Sobre esse aspecto, Dworkin assevera que a aplicação do direito tem como pressuposto assegurar ao destinatário da aplicação da norma jurídica a segurança necessária, já que a atividade interpretativa deve ser despida dos aspectos morais do aplicador do direito positivo ${ }^{05}$.

A norma jurídica no paradigma do positivismo jurídico é entendida como sinônimo de texto legal, o que de certo modo provoca o esvaziamento da atividade

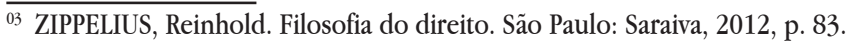

${ }^{04}$ MASCARO, Alysson Leandro. Filosofia do Direito. 2. ed. São Paulo: Atlas, 2012, p. 34.

${ }^{05}$ DWORKIN, Ronald. Law's empire. Cambridge: Harvard University Press, 1986, p. 114.
} 
hermenêutica, diante da diminuição das possibilidades de valoração por parte do exegeta, ainda que várias possibilidades interpretativas sejam de possível obtenção do texto de lei. A teoria de Kelsen, em sua primeira fase, coloca em um segundo plano de importância a questão relativa ao problema da interpretação diante do caso concreto $^{06}$.

A separação da realidade fática do direito evidencia uma contradição em si do positivismo jurídico, tudo isso como forma de assegurar a ideia de segurança jurídica e o purismo da ciência do direito. A ciência jurídica é um ramo das ciências sociais aplicadas e tem como objetivo central a regulação das relações sociais. Afastar o direito da realidade fática evidencia insuperável contradição.

Friedrich Müller ${ }^{07}$ destaca, acerca da relação que deve haver entre o direito e a realidade social, que "a premissa de um dos erros mais fundamentais do positivismo na ciência jurídica, a compreensão e o tratamento da norma jurídica como algo que repousa em si e preexiste, é a separação da norma e dos fatos, do direito e da realidade".

O processo evolutivo do pensamento kelseniano, em um segundo momento do positivismo jurídico, caminhou no sentido de sustentar a possibilidade de diversidade interpretativa do direito dentro da moldura normativa, ante o reconhecimento do caráter plurissignificação das palavras presentes no texto normativo, ainda que mantida a posição anterior de secundarizar a facticidade.

$O$ processo hermenêutico era tido para Kelsen ${ }^{08}$, nessa segunda fase do pensamento científico, como

[... ] a fixação por via cognoscitiva do sentido do objeto a interpretar, o resultado de uma interpretação jurídica somente pode ser a fixação da moldura que representa o Direito a interpretar e, consequentemente, o conhecimento das várias possibilidades que dentro desta moldura existem.

A possibilidade de o aplicador do direito obter diversas interpretações possíveis $^{09}$, dentro ou até mesmo fora da moldura normativa ${ }^{10}$, de certa forma fragilizou o pilar do juspositivismo, que tem como eixo central a segurança jurídica e a estabi-

\footnotetext{
${ }^{06}$ STRECK, Lênio Luiz. O (pós-) positivismo e os propalados modelos de juiz (Hércules, Júpiter e Hermes) - dois decálogos necessários. Revista de Direitos e Garantias Fundamentais, Vitória, n. 7, p. 30, jan.jun. 2010.

${ }^{07}$ MÜLLER, Friedrich. Teoria estruturante do direito. 3. ed. rev. atual. São Paulo: Revista dos Tribunais, 2011, p. 19.

${ }^{08}$ KELSEN, Hans. Teoria pura do direito. Tradução de João Baptista Machado. 6. ed. São Paulo: Martins Fontes, 1998, p. 390.

${ }^{09}$ PERLINGIERI, Pietro. Perfis do direito civil: introdução ao direito civil constitucional. 2. ed. Rio de Janeiro: Renovar, 2002, p. 62.

${ }^{10}$ KELSEN, Hans, op cit., 1998, p. 394.
} 
lização da interpretação do direito positivado.

O permissivo para a discricionariedade judicial colocou em risco a segurança jurídica na atividade interpretativa, uma vez que a decisão a ser adotada pelo aplicador do direito dentro ou mesmo fora da moldura normativa, sendo esta última admitida na última fase do pensamento de Hans Kelsen, era reconhecida como legítima e, portanto, justa, já que os critérios de aferição desses elementos eram meramente formais.

A modificação dos perfis de conflitos na sociedade de massificada, que transcendem a individualidade dos envolvidos, evidenciou a verdadeira utopia da pretensão de completude do ordenamento jurídico. A natureza metaindividual dos conflitos de interesses, muitos deles oriundos da própria evolução tecnológica, minou a própria base do juspositivismo, que tem como pressuposto a existência de um ordenamento jurídico sem lacunas.

O Estado democrático de Direito exigiu do intérprete autêntico, em razão da massificação dos conflitos sociais e da natureza metaindividual dos interesses a ser tutelados pelo Estado, um novo olhar relacionado com a realidade fática. O novo paradigma de Estado, fundado no papel central a ser ocupado pela Constituição, supera a concepção do positivismo jurídico de que esta tem o papel apenas de parametrizar a aferição de validade da norma jurídica. Assumem as Constituições no Estado democrático de Direito a força normativa própria capaz de autorizar o aplicador do direito a possibilidade de construção de normas jurídicas no caso concreto, inclusive a partir dos seus princípios estruturantes.

Os princípios contidos nas Constituições deixam de ocupar espaço secundário de meras fontes supletivas para colmatar lacunas, assumindo força normativa própria. A carga axiológica dos princípios constitucionais autoriza ao aplicador do direito maior plasticidade na atividade interpretativa, adequando o texto legal à realidade fática.

O papel central da Constituição ${ }^{11}$ permitiu uma nova compreensão da teoria da norma jurídica, a partir da inclusão de novas fontes com normatividade própria, como é o caso dos princípios constitucionais. A necessidade da reaproximação entre a moral e o direito positivo e dos campos do "ser" e do "dever-ser" passou a demandar do intérprete autêntico maior preocupação com a justiça da decisão no caso concreto.

Essa nova corrente jusfilosófica é denominada como pós-positivismo jurí-

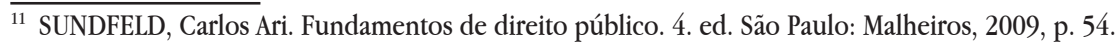


dico, que representa "a concepção teórica do neoconstitucionalismo"12. Rachel Nigro $^{13}$, acompanhando esse movimento, reconhece o fenômeno do neoconstitucionalismo como expressão de um "movimento inserido no paradigma pós-positivista".

O pós-positivismo jurídico tem como pressuposto o papel central a ser ocupado pela Constituição no ordenamento jurídico, o que permite o reconhecimento da importância dos seus princípios, ante a sua força normativa ${ }^{14}$, além de servir como verdadeiros vetores hermenêuticos ao aplicador do direito.

Luís Roberto Barroso ${ }^{15}$ destaca que o pós-positivismo jurídico representa uma nova aproximação entre antigos paradigmas antagonistas: o jusnaturalismo e o juspositivismo, em razão da necessidade de uma leitura moral do direito, preocupado com a realidade fática.

Essa aproximação representa a busca do pós-positivismo em “(...) ir além da legalidade estrita, mas não despreza o direito posto; procura empreender uma leitura moral do Direito, mas sem recorrer a categorias metafísicas"16.

Pretende Coleman, no sentido de incluir, reconhecer que os aspectos do campo da moral devem ser considerados pelo aplicador do direito na atividade interpretativa, bem como no reconhecimento da validade de determinada norma jurídica positivada ${ }^{17}$.

A preocupação com a higidez do direito positivado permanece nesse novo modelo jurídico-filosófico, tendo em vista o caro valor da segurança jurídica, indispensável à sociedade da pós-modernidade.

A preocupação com os aspectos morais, por outro lado, garante ao aplicador do direito efetuar juízo de valor acerca da melhor interpretação a ser conferida ao texto da norma jurídica, diante da aproximação da atividade hermenêutica com elementos do campo do "ser". A tarefa de aplicar o direito positivado deixa de ser mero ato de vontade, como no juspositivismo clássico kelseniano ${ }^{18}$.

O pós-positivismo jurídico é caracterizado, segundo Ricardo Fernandes e

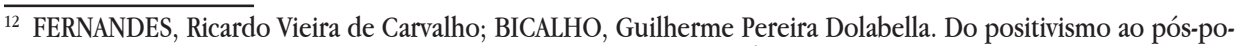
sitivismo jurídico. Revista de informação legislativa, Brasília, ano 48, n. 189, p. 120, jan./mar. 2011.

${ }^{13}$ NIGRO, Rachel. A virada linguístico-pragmática e o pós-positivismo. Revista Direito, Estado e Sociedade, Rio de Janeiro, n. 34, p.190, jan.jun. 2009.

${ }^{14}$ KIM, Richard Pae. Neoconstitucionalismo: hermenêutica constitucional e atividade jurisdicional na tutela dos direitos do cidadão. Revista da Ajuris, Porto Alegre, ano XXXVI, n. 116, p. 272, dez. 2009.

${ }^{15}$ BARROSO, Luís Roberto. Neoconstitucionalismo e constitucionalização do direito. Boletim de direito administrativo, São Paulo, ano 23, n. 1, p. 22, jan. 2007.

${ }^{16}$ Idem.

${ }^{17}$ COLEMAN, Jules. The practice of principle: in defence of a pragmatist approach to legal theory. New York: Oxford, 2003, p. 77.

${ }^{18}$ KELSEN, Hans. op cit., 1998, p. 394. 
Guilherme Bicalho ${ }^{19}$, pela "abertura valorativa do sistema jurídico e, sobretudo, da Constituição", pela força normativa atribuída aos princípios, que passam a ter a mesma força das regras, pela centralidade das Constituições como fontes de princípios e, por fim, pelo "aumento da força política do Judiciário em face da constatação de que o intérprete cria norma jurídica".

A superação da tese que separa o "ser" do "dever-ser" e a busca de aproximar o direito da moral permitiram o pós-positivismo jurídico superar a base juspositivista clássica de que a norma jurídica é sinônimo de texto legal e que a norma jurídica não é algo dado pelo legislador, mas construída diante do caso concreto pelo intérprete autêntico durante o julgamento.

A atividade do Poder Judiciário passa a ser renovada, já que os órgãos judicantes passam a protagonizar o papel de criação da norma jurídica, diante da preocupação com a efetividade da tutela jurisdicional ${ }^{20}$. Essa atividade somente é possível diante da abertura dada pelo texto e pelos princípios da Constituição no Estado democrático de Direito.

A atividade criadora da norma jurídica autorizada no pós-positivismo jurídico demanda a existência de mecanismos de controle, diante da exigência de segurança jurídica, de modo a evitar a existência de discricionariedade judicial. Esses mecanismos de controle, outrossim, são ainda capazes de afastar as críticas dos convencionalistas, para quem o papel do aplicador do direito deve ser cingido à aplicação do direito, sem a possibilidade de qualquer atividade criativa ${ }^{21}$.

A teoria estruturante da norma jurídica, desenvolvida por Friedrich Müller ${ }^{22}$, é apresentada no pós-positivismo jurídico como mecanismo de controle da discricionariedade judicial, atendendo às necessidades de assegurar a segurança jurídica, de aproximação dos campos do "ser" e do "dever-ser" e de conferir mais que a legitimidade meramente formal aos aplicadores do direito.

A aplicação da teoria estruturante do direito no cenário pós-positivista, considerando o seu pressuposto de criação da norma jurídica no caso concreto, é capaz de conferir a legitimidade necessária à atividade de criação da norma jurídica por parte dos órgãos do Poder Judiciário, conforme será a seguir analisado.

\section{A INSERÇÃO DA TEORIA ESTRUTURANTE DA NORMA DE FRIEDRICH}

\footnotetext{
${ }^{19}$ FERNANDES, Ricardo Vieira de Carvalho; BICALHO, Guilherme Pereira Dolabella. Do positivismo ao pós-positivismo jurídico. Revista de informação legislativa, Brasília, ano 48, n. 189, p. 114, jan./mar. 2011.

${ }^{20}$ POZZOLO, Susanna. Un constitucionalismo ambiguo. In: CARBONELL, Miguel (Org.). Neoconstitucionalismo (s). 4. ed. Madri: Editorial Trota, 2009, p. 190.

${ }^{21}$ DWORKIN, Ronald. Law's empire. Cambridge: Harvard University Press, 1986, p. 120.

${ }^{22}$ MÜLLER, Friedrich. Teses sobre a estrutura das normas jurídicas. Revista dos Tribunais, São Paulo, ano 102, vol. 929, p. 200, mar. 2013.
} 


\section{MÜLLER NO PÓS-POSITIVISMO JURÍDICO}

O juspositivismo propõe a independência do direito positivado com a realidade fática em nome de um método puro de compreensão do fenômeno jurídico. O positivismo jurídico é alicerçado na separação entre os domínios do "ser" e do "dever-ser", incapaz de rebater às demandas apresentadas pela sociedade da pósmodernidade, caracterizada pela massificação dos conflitos sociais.

Direito e a realidade dos fatos, conforme anteriormente pontuado, são capazes de gerar a influência recíproca ${ }^{23}$. Qualquer forma de afastamento da norma jurídica com a realidade fática que objetiva regular deve ser repelida $a^{24}$. O silogismo na aplicação estática do direito positivado à situação fática apresentada, típico do modelo do juspositivista, apresentou sua insuficiência na solução das demandas da sociedade contemporânea.

Sob esse novo momento da sociedade e da ciência jurídica, representado pelo papel central ocupado pela Constituição e pelo imperativo de reaproximação da realidade com o direito positivado, o pós-positivismo jurídico reconheceu a possibilidade de o intérprete autêntico elaborar a norma jurídica diante do caso concreto $^{25}$, superando o modelo do positivismo jurídico que compreendia a norma jurídica como sinônimo do texto legal e, portanto, como algo pronto e estático após a elaboração pelo órgão de produção legislativa.

A teoria estruturante da norma jurídica é apresentada no pós-positivismo jurídico como uma doutrina associada ao realismo jurídico, diante da reaproximação do direito com os fatos sociais. A teoria estruturante da norma, desenvolvida por Friedrich Müller, objetiva

[...] uma argumentação e decisão integral, cujo processo pode ser mentalmente refeito [isto é. controlado por outros juristas, outros juízes/tribunais] e que tem natureza igualitária, com base e no quadro do direito vigente - e nisso sempre amparado nos fatos do caso individual e nos fatos/suportes fáticos genéricos do tipo do caso. Não se trata, portanto, de um pragmatismo geral, ideológico, mas de um pragmatismo formado pelos conceitos e modi operandi teórico-metodológicos e operacionalizado nos detalhes desses mesmos conceitos e modi operandi. Assim o "direito" e a "realidade" não aparecem

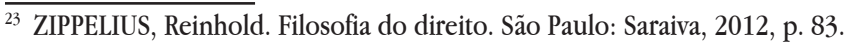

${ }^{24}$ MÜLLER, Friedrich. Teoria estruturante do direito. 3. ed. rev. atual. São Paulo: Revista dos Tribunais, 2011, p. 11.

${ }^{25}$ FERNANDES, Ricardo Vieira de Carvalho; BICALHO, Guilherme Pereira Dolabella. Do positivismo ao pós-positivismo jurídico. Revista de informação legislativa, Brasília, ano 48, n. 189, p. 114, jan./mar. 2011.
} 
mais como categorias opostas abstratas; eles atuam agora como elementos da ação jurídica, sintetizáveis no trabalho jurídico efetivo de caso para caso - na forma da norma jurídica produzida. E essa ação jurídica é uma ação pela e na linguagem [Sprachbandeln], é geração do texto com base em textos, inscreve-se na estrutura textiforme da democracia fundada no Estado de Direito ${ }^{26}$.

A autorização para a criação normativa diante do caso concreto representa uma forma de manifestação de incremento de poder conferido ao Poder Judiciário, o que poderia ensejar o questionamento acerca da legitimação dessa atividade realizada por órgãos não escolhidos pelo povo. De forma a assegurar a legitimidade dessa atuação criativa, tem-se que o princípio da segurança jurídica, uma das principais bases do positivismo jurídico e do próprio Estado democrático de Direito, assume novos contornos no pós-positivismo jurídico, com o foco em evitar a discricionariedade judicial.

A possibilidade de outro órgão judicial realizar o controle do caminho percorrido pelo julgador originário na construção da norma jurídica diante do caso concreto é a garantia contra o pragmatismo judicial e eventuais arbitrariedades, bem como tem função de imprimir uma legitimidade material e não apenas formal à decisão tomada pelo intérprete autêntico.

A dinâmica conferida pela teoria estruturante da norma, que tem o texto da norma jurídica como etapa inicial na atividade de realização concreta da norma jurídica $^{27}$, garante a higidez de princípios constitucionais fundantes do Estado de direito Democrático como o da separação dos poderes e o da segurança jurídica.

A teoria desenvolvida por Friedrich Müller resguarda, sobretudo, a sociedade contra as escolhas discricionárias do órgão julgador diante da moldura normativa, bem como situações de aplicação inversa do silogismo jurídico, onde o texto de lei é utilizado para fundamentar uma decisão formada a priori.

A teoria estruturante do direito não se propõe à revelação da norma jurídica, mas a sua própria elaboração de modo metodicamente estruturado, a partir de signos linguísticos e dos dados da realidade apresentados pelo caso concreto apresentado ao órgão julgador. A norma jurídica é inexistente antes da ocorrência da

\footnotetext{
${ }^{26}$ MÜLLER, Friedrich. O novo paradigma do direito: introdução à teoria e metódica estruturantes do direito. 3. ed. São Paulo: Revista dos Tribunais, 2013, p. 13.

${ }^{27}$ ADEODATO, João Maurício. Ética e retórica: para uma teoria da dogmática jurídica. São Paulo: Saraiva, 2002, p. 222.
} 
situação fática em que se pretende uma solução jurídica ${ }^{28}$, o que é capaz de afastar qualquer compreensão de que a atividade interpretativa é meramente declaratória.

João Maurício Adeodato ${ }^{29}$ adverte que a teoria estruturante do direito, desenvolvida por Friedrich Müller, não tem como objetivo desenvolver uma sistemática que garanta uma única solução correta para o caso concreto. A metódica racional dessa teoria assegura ao intérprete autêntico, independentemente do ramo do direito envolvido ${ }^{30}$, a construção da norma jurídica no caso concreto, a partir dos signos linguísticos.

A teoria estruturante do direito é apresentada em uma sequência de 11 passos, que, segundo apresentação de João Maurício Adeodato ${ }^{31}$, são assim elencados: Sprachdaten, Realdaten, Normtexte, Fallerzäblung, Sachverhalt, Sachbereich, Fallbereich, Normprogramm, Normbereich, Rechtsnorm e Entscheidungsnorm ${ }^{32}$. As citadas etapas até a concretização da norma serão desenvolvidas e analisadas de forma pormenorizada na seção subsequente.

\section{AS ETAPAS DO PROCESSO DECISÓRIO NO ESTADO DE DIREITO DEMOCRÁTICO A PARTIR DA METÓDICA JURÍDICA ESTRUTURANTE}

A teoria estruturante da norma, inserida no paradigma do pós-positivismo jurídico, está longe de representar uma ruptura com o modelo do positivismo jurídico clássico, já que manteve algumas de suas bases fundantes.

O juspositivismo tem como um dos seus alicerces a garantia da segurança jurídica nas relações sociais que objetiva regular. O positivismo jurídico parte em sua dogmática do conteúdo do texto de lei como base de interpretação do direito e meio de assegurar a segurança jurídica. Ainda que se parta do método filológico ou gramatical para a interpretação do texto do direito positivado, tem-se que a norma jurídica

${ }^{28}$ MÜLLER, Friedrich. O novo paradigma do direito: introdução à teoria e metódica estruturantes do direito. 3 . ed. São Paulo: Revista dos Tribunais, 2013, p.11.

29 ADEODATO, João Maurício. Ética e retórica: para uma teoria da dogmática jurídica. São Paulo: Saraiva, 2002, p. 252.

30 MÜLLER, Friedrich. Teses sobre a estrutura das normas jurídicas. Revista dos Tribunais, São Paulo, ano 102, vol. 929, p. 200, mar. 2013.

${ }^{31}$ ADEODATO, João Maurício. Norma jurídica como decisão dotada de efetividade. Revista Jurídica da Presidência, Brasília, v. 15, n. 106, p. 312, jun./set. 2013.

${ }^{32}$ Em tradução livre, os onze passos do processo de concretização da norma jurídica são definidos como: dados linguísticos da norma, relatos ou dados reais, conjunto de matérias, relato leigo do caso, circunstância da espécie, âmbito do caso, programa da norma, âmbito da norma, norma jurídica e norma de decisão. 
e o texto da norma são apresentados como entidades autônomas, inconfundíveis entre si, ante o caráter plurissignificativo que os verbetes apresentam, suscetíveis de induzir múltiplas interpretações.

A teoria estruturante da norma tem como ponto de partida a análise dos elementos textuais contidos na obra do órgão legislador, como base para a construção da norma jurídica. São buscados, nesse primeiro momento, dentro do sistema jurídico os elementos linguísticos e filológicos presentes nos elementos estruturais dos textos legais como nos artigos, nos incisos, nos parágrafos e nas alíneas como primeiro passo na atividade de concretização do direito.

O texto da norma representa na visão de Friedrich Müller ${ }^{33}$ a "ponta do iceberg", ou, como destaca com propriedade Christiany Pegorari Conte ${ }^{34}$, "apenas um ponto de partida para a concretização, bem como um limite para a concretização legal e legítima, posto que possui, como premissas, os preceitos de um Estado Democrático de Direito".

Os elementos filológicos e gramaticais do texto legal constituem o limite hermenêutico ${ }^{35}$, o que permite conferir legitimidade ao intérprete autêntico do direito na atividade de concretização da norma jurídica.

Os métodos tradicionais de interpretação do direito, como a interpretação gramatical, representam a primeira etapa rumo à concretização da norma jurídica, tendo em vista a utilização da estrutura do texto da lei como limite normativo e hermenêutico.

O método de interpretação gramatical estabelece o sentido linguístico do texto legislado, por meio da representação dos sentidos filológicos possíveis de extração a partir dos verbetes ou conjuntos de palavras e expressões. Carlos Maximiliano já afirmava que o processo de interpretação a partir da literalidade, em razão da complexidade da língua portuguesa, demanda do aplicador do direito diversos predicados, dentre eles:

1) conhecimento perfeito da língua empregada no texto, isto é, das palavras e frases em determinado tempo e lugar; propriedades e acepções várias de cada uma delas; leis de composição; gramática; 2 )

\footnotetext{
${ }_{33}$ MÜLLER, Friedrich. Metodologia do direito constitucional. 4. ed. rev. atual. e ampl. São Paulo: Revista dos Tribunais, 2010, p. 54.

${ }^{34}$ CONTE, Christiany Pegorari. A aplicabilidade da teoria estruturante no direito contemporâneo face à crise do positivismo clássico. In: XVII Congresso Nacional do CONPEDI. Anais do XVII Congresso Nacional do CONPEDI. Brasília: http://www.conpedi.org.br/anais_brasilia.html, 2008, p. 5960.

35 MÜLLER, Friedrich. Metodologia do direito constitucional. 4. ed. rev. atual. e ampl. São Paulo: Revista dos Tribunais, 2010, p. 33.
} 
informação relativamente segura, e minuciosa quanto possível, sobre a vida, profissão, hábitos pelo menos intelectuais e estilo do autor; orientação do seu espírito, leituras prediletas, abreviaturas adotadas; 3) notícia completa do assunto de que se trata, inclusive a história respectiva; 4) certeza da autenticidade do texto, tanto em conjunto como em cada uma das suas partes ${ }^{36}$.

O método de interpretação gramatical permite a extração dos diversos significados possível dos verbetes utilizados no texto da norma, separando aqueles de cunho cotidiano ou do senso comum, com aqueles outros estabelecidos pela ciência do direito ${ }^{37}$. A característica da plurissignificação dos verbetes atesta por si só a incapacidade do método gramatical fixar o conteúdo da norma jurídica.

Como já destacado anteriormente, além dos dados linguísticos do texto positivado, a atividade hermenêutica compreende nessa etapa de concretização a observância de outras metodologias interpretativas, que funcionam de forma suplementar como os métodos sistemático, histórico e genético ${ }^{38}$.

O método de interpretação sistemático tem o objetivo de "comparar o dispositivo sujeito a (sic!) exegese, com outros do mesmo repositório ou de leis diversas, mas referentes ao mesmo objeto" ${ }^{\text {39 }}$. Essa metodologia de interpretação do direito permite a contextualização do texto normativo em si com o conjunto do ordenamento jurídico, assegurando uma interpretação integrada.

Outras metodologias tradicionais de interpretação complementar aos métodos gramatical e sistemático são apresentadas ao intérprete na atividade de concretização da norma jurídica. O método interpretativo histórico funciona como verdadeiro mecanismo de compreensão do alcance do texto da norma, pois permite buscar no processo legislativo os princípios e as ideologias que contribuíram no processo de elaboração do texto normativo pelo órgão legiferante.

Não obstante a relevância do método interpretativo histórico na construção da norma jurídica, deve ser destacado que este método também revela sua insuficiência, se tomado de forma isolada, em razão do próprio caráter cambiante do direito, como ciência social aplicada.

O método interpretativo genético "prende-se aos elementos e processos sociais que efetivamente deram a feição com a qual o texto se mostra agora, como

\footnotetext{
${ }^{36}$ MAXIMILIANO, Carlos. Hermenêutica e aplicação do direito. 20. ed. Rio de Janeiro: Forense, 2013, p. 88.

${ }^{37}$ MÜLLER, Friedrich. O novo paradigma do direito: introdução à teoria e metódica estruturantes do direito. 3 . ed. São Paulo: Revista dos Tribunais, 2013, p. 64.

${ }^{38}$ ADEODATO, João Maurício. Ética e retórica: para uma teoria da dogmática jurídica. São Paulo: Saraiva, 2002, p. 238.

${ }^{39}$ MAXIMILIANO, Carlos. Hermenêutica e aplicação do direito. 20. ed. Rio de Janeiro: Forense, 2013, p. 104.
} 
quando se estudam os anais da Constituinte" ${ }^{\sharp 0}$. A utilização deste método interpretativo permite extrair do texto legal os elementos sociais que influenciaram o processo de elaboração do texto normativo.

Os métodos histórico e genético são interligados, em razão da referência ao cenário de elaboração do texto legal, e funcionam como "pontos de vista auxiliares no âmbito do aspecto gramatical" ${ }^{11}$, capazes de auxiliar na precisão dos possíveis sentidos dos elementos textuais.

A teoria estruturante da norma afasta a utilização da interpretação teleológica na primeira etapa da construção da norma jurídica. Essa desconsideração é motivada pela ausência de autonomia deste método interpretativo tradicional, em relação aos métodos gramatical, histórico, sistemático e genético ${ }^{42}$.

Friedrich Müller ${ }^{43}$ adverte que a aplicação do método interpretativo teleológico, ainda que não possa ser totalmente desconsiderada, deve ser pautada com a devida cautela pelo operador do direito, já que a mesma pode ter o poder de ocultar, em razão da busca da finalidade da norma jurídica, os elementos concretos indispensáveis na atividade de concretização da norma jurídica, em razão de preconcepções do próprio intérprete autêntico. A norma jurídica a ser construída no caso concreto deve ser vista para além dos seus elementos abstratos, observando também os elementos fáticos e reais do caso apresentado a julgamento.

O primeiro passo na concretização da norma jurídica é representado pela utilização dos métodos hermenêuticos tradicionais. O papel do texto da norma, na primeira etapa, é o de estabelecer os contornos gerais da norma jurídica a ser construída, que serão conformados com elementos do caso concreto, como veremos nos próximos momentos da sistematização da teoria estruturante da norma.

Conforme já destacado na primeira etapa do processo de construção da norma jurídica, os elementos linguísticos do texto normativo representam apenas os aspectos visíveis na atividade de concretizar o direito, ou seja, a "ponta do iceberg"44 de onde parte o operador do direito na atividade intelectiva.

O purismo do elemento textual revelou a sua insuficiência no processo

\footnotetext{
${ }^{40}$ ADEODATO, João Maurício. Ética e retórica: para uma teoria da dogmática jurídica. São Paulo: Saraiva, 2002, p. 238.

${ }^{41}$ MÜLLER, Friedrich. Metodologia do direito constitucional. 4. ed. rev. atual. e ampl. São Paulo: Revista dos Tribunais, 2010, p. 76.

${ }^{42}$ Ibidem, p. 77.

${ }^{43}$ MÜLLER, Friedrich. O novo paradigma do direito: introdução à teoria e metódica estruturantes do direito. 3 . ed. São Paulo: Revista dos Tribunais, 2013, p. 64.

${ }^{44}$ Ibidem, p. 86.
} 
criativo da norma, ante a necessidade de aproximação com os elementos fáticos e circunstanciais do caso concreto apresentado ao operador do direito. Os dados da realidade concreta são apresentados como fatores relevantes na atividade de construção da norma jurídica, considerando que direito e realidade são influenciáveis entre si. Daí porque não é possível, à luz da teoria estruturante do direito, a existência de uma norma jurídica a priori do caso concreto apreciado pelo Poder Judiciário.

As informações da realidade ou os dados reais (Realdaten) devem ser necessariamente considerados pelo intérprete autêntico na atividade de realização concreta da norma jurídica.

A busca de subsídios e de elementos do mundo fático constitui a segunda etapa no processo de concretização da norma jurídica. São considerados como dados reais os elementos fáticos tomados como verdades indiscutíveis ou decorrentes de uma relação lógica (relação de causa e efeito) pelo senso comum.

Pode ser tomado como situação exemplificativa de "dados reais", no âmbito do direito do trabalho, o fato de um trabalhador, que exerce sua atividade exposto ao sol, sem equipamentos de proteção, apresentar maior risco de adquirir câncer de pele, ou do trabalhador que labora em sobrelabor habitual apresentar maior risco de acidente por fadiga.

Os elementos da realidade fática, ainda que sejam provenientes do senso comum ou que sejam impassíveis de discussão quanto à existência, devem ser ponderados pelo intérprete durante a atividade de construção da norma jurídica.

A atividade de concretização da norma jurídica não se limita à apreensão de dados da realidade no processo construtivo, mas também do conhecimento integrado de todo o ordenamento jurídico. Esse momento no processo construtivo da norma jurídica é denominado de Normtexte.

O terceiro momento do processo decisório da dogmática apresentada por Friedrich Müller exige do aplicador do direito a tarefa de observar e de realizar o levantamento dos textos normativos presentes no ordenamento jurídico, o que inclui os textos da Constituição, das leis complementares, das leis ordinárias, dos decretos, dos regulamentos, inclusive das súmulas, vinculantes ou não, orientações jurisprudenciais e portarias editadas pelos Tribunais.

A etapa do Normtexte distingue-se do método de interpretação sistemática utilizado pelo paradigma do positivismo jurídico na atividade de revelar a norma jurídica, pois como bem lembra João Maurício Adeodato, nesta etapa de concretização 
"não se observa ainda nenhum texto específico, como um artigo ou parágrafo de lei, porque ainda não se está diante de caso concreto" ${ }^{45}$.

$\mathrm{O}$ aspecto abstrato desta etapa do processo de concretização da norma jurídica exige do intérprete apenas a realização do levantamento dos textos legais, que poderão ser utilizados quando apresentado o caso concreto a julgamento pelo órgão judicial.

A quarta etapa do processo de concretização da norma jurídica é representado pelo relato leigo do caso ou Fallerzählung. O intérprete neste momento verificará, a partir dos relatos e dos demais dados trazidos pelas partes em depoimentos pessoais, de testemunhas, de peritos, de autoridades responsáveis pela fiscalização, quais são os dados relevantes para a análise dogmática, a partir do ordenamento jurídico abstratamente levantado na terceira etapa.

João Maurício Adeodato ${ }^{46}$ destaca que a etapa do relato leigo do caso representa "a maneira pela qual o caso em questão chega ao conhecimento do profissional do direito", ou seja, sem a roupagem jurídica no discurso linguístico.

No âmbito do direito material do trabalho, servem como exemplos de manifestações do relato leigo do caso as narrativas e as informações prestadas pelas partes durante o depoimento pessoal ou pelas testemunhas e demais auxiliares do juiz de que "o trabalhador não usava equipamentos de proteção", "o trabalhador ia para o trabalho caminhando, pois residia próximo do ambiente laboral", dentre outros relatos fáticos.

Uma vez apresentada a narrativa leiga do caso, torna-se indispensável a atividade do intérprete, conhecedor do ordenamento jurídico, em realizar a filtragem das circunstâncias fáticas essenciais para o deslinde da controvérsia. A atividade de separação dos aspectos fáticos relevantes pelo operador do direito, diante da apresentação do relato leigo do caso, constitui a quinta etapa no processo de concretização da norma jurídica, denominada por Friedrich Müller como a circunstância da espécie ou o conjunto de matérias (Sachverhalt).

O operador do direito, que tem conhecimento do conjunto de textos que compõem o ordenamento jurídico, inclusive das súmulas e das orientações jurisprudenciais dos Tribunais, realiza nesta etapa a clivagem dos fatos efetivamente rele-

\footnotetext{
${ }^{45}$ ADEODATO, João Maurício. Norma jurídica como decisão dotada de efetividade. Revista Jurídica da Presidência, Brasília, v. 15, n. 106, p. 312, jun./set. 2013.

${ }^{46}$ ADEODATO, João Maurício. Ética e retórica: para uma teoria da dogmática jurídica. São Paulo: Saraiva, 2002, p. 242.
} 
vantes para o caso concreto, separando dos demais elementos fáticos trazidos pelos relatos leigos.

A segregação realizada pelos juristas entre fatos relevantes e fatos irrelevantes, a partir dos elementos fáticos trazidos do relato leigo, objetiva a delimitação do âmbito da matéria. São buscadas pelo operador do direito as hipóteses dispostas nos textos normativos como sendo adequadas para aqueles fatos selecionados. Chega-se, a partir desse procedimento metódico, na delimitação do âmbito da matéria (Sacbbereich).

O jurista no processo de delimitação do âmbito da matéria vai além da mera seleção de textos legais referenciada no terceiro momento da metódica estruturante. $\mathrm{Na}$ etapa do Sachbereich, "o jurista procura os artigos e parágrafos, os textos que poderiam ser relevantes para o caso que tem diante de si, e ao mesmo tempo observa a realidade, para nela descobrir informações e dados fáticos que poderiam ser significativos" ${ }^{\prime 7}$.

Valendo de exemplos no âmbito da medicina e da segurança do trabalho, servem como situações ilustrativas da delimitação do âmbito da matéria, a constatação pelo intérprete autêntico da existência ou não de realização de horas suplementares por parte do trabalhador, da ausência de pausas para descanso e alimentação a partir da quarta hora trabalhada, a não realização pelos digitadores de intervalo a cada 50 minutos nos termos da Norma Regulamentadora $\mathrm{n}^{0} 17$ do Ministério do Trabalho e Emprego, a concessão de folga compensatória nas situações em que houve labor no dia destinado ao descanso semanal remunerado, a existência de fiscalização na utilização de equipamentos de proteção individual, dentre outras tantas.

Observam-se também nessa etapa do processo de concretização os textos legais aplicáveis, que no caso de questões relativas à segurança e à medicina do trabalho são a Constituição, a Consolidação das Leis do Trabalho, as Normas Regulamentadoras do Ministério do Trabalho e Emprego, o Código de Processo Civil (em aspectos processuais da tutela de direitos), e os demais diplomas legais.

Vencida a etapa da fixação do âmbito da matéria na metódica estruturante, passa-se a definição do sétimo passo, ou seja, a definição do âmbito do caso ou Fallbereich. A aferição do âmbito do caso demanda do intérprete autêntico relacionar o âmbito da matéria ou Sachbereich com as peculiaridades apresentadas pelo caso concreto posto à apreciação.

Seguindo a mesma sistematização utilizada na apresentação das demais $\overline{47}$ Ibidem, 2002, p. 246. 
etapas, a partir de exemplos em matéria de segurança e de medicina do trabalho, verifica-se no âmbito do direito do trabalho se o trabalhador realiza outras atividades durante o trabalho exposto ao sol, se aquele digitador era substituído ou não periodicamente por outro colega de trabalho durante a jornada, se havia ou não a rotatividade na execução das tarefas, o tempo de efetiva jornada de trabalho, a periodicidade de troca dos equipamentos de proteção individual, dentre outras circunstâncias do caso concreto.

A oitava etapa no processo de concretização da norma jurídica ocorre após a seleção dos textos de norma realizada no sexto passo da metódica estruturante. Realizada a seleção dos textos da norma, é feita a interpretação dos mesmos à luz dos fatos selecionados como relevantes para o deslinde da controvérsia posta. A partir dai é possível a construção do programa da norma ou Normprogramm.

O programa da norma, portanto, representa o resultado de todas as interpretações linguísticas possíveis ${ }^{48}$, mediante a utilização dos métodos tradicionais de interpretação empreendidos pelo positivismo e apresentados anteriormente (gramatical, sistemático, histórico, genético e teleológico).

Friedrich Müller ${ }^{49}$ destaca que, em havendo eventuais contradições na interpretação por meio da aplicação dos métodos tradicionais, os elementos gramatical e sistemático nesta etapa devem prevalecer em detrimento dos métodos histórico e genético, já que os primeiros se relacionam ao texto da norma e, consequentemente, estabelecem os contornos normativos.

Ao ser atribuída preponderância aos elementos linguísticos do texto legal estabelecidos pelo órgão legiferante, é conferida maior legitimação à atividade de concretização da norma jurídica, já que, de forma reflexa, são respeitados os princípios gerais do Estado democrático de Direito como, por exemplo, o da separação dos poderes, o da legalidade e o da segurança jurídica. O Poder Legislativo, ao elaborar o texto da norma, estabelece a priori os seus contornos gerais, que devem ser observados e respeitados pelo intérprete autêntico, durante a atividade de concretização.

A etapa de fixação do programa da norma exige do intérprete não apenas a utilização dos métodos tradicionais de interpretação, como a utilização dos métodos gramatical e sistemático, mas também devem que sejam observados "os elementos

\footnotetext{
${ }^{48}$ MÜLLER, Friedrich. O novo paradigma do direito: introdução à teoria e metódica estruturantes do direito. 3. ed. São Paulo: Revista dos Tribunais, 2013, p. 135.

${ }^{49}$ MÜLLER, Friedrich. Metodologia do direito constitucional. 4. ed. rev. atual. e ampl. São Paulo: Revista dos Tribunais, 2010, p. 97.
} 
de técnica da solução, os elementos dogmáticos, de política constitucional e de teoria" ${ }^{\prime 0}$.

Estabelecido o programa da norma, a partir de informações extraídas por meio da interpretação gramatical e sistemática da linguagem textual ${ }^{51}$, passa-se a outra atividade no de concretização da norma jurídica, ou seja, o estabelecimento do âmbito da norma ou Normbereich.

$\mathrm{O}$ âmbito da norma constitui-se a partir do

[...] resultado da aplicação do programa da norma (Normprogramm) ao conjunto de matérias (Sachverbalt) obtido no quinto passo, ou seja, o âmbito da norma refere-se a dados empíricos, aos elementos do âmbito do caso que foram por sua vez selecionados pelo programa da norma ${ }^{52}$.

O âmbito da norma é constituído, portanto, pela seleção dos dados da realidade fática efetivamente relevante, à luz do direito positivo. São considerados, por exemplo, fatos da realidade que merecem relevância, no âmbito da segurança e da medicina do trabalho, situações em que empregador que deixa de fornecer o mobiliário ergonômico para o desempenho das atividades, ou que não entrega os equipamentos de proteção individual, ou mesmo que não concede o intervalo intrajornada para repouso e alimentação do trabalhador. Tais fatos sociais são considerados relevantes à luz do direito positivo, quando o intérprete autêntico é posto a apreciar questões relativas à saúde do trabalhador.

Em contraposição, situações fáticas secundárias como, exemplificativamente, correlacionadas à situação do empregado que faz seu deslocamento para o local de trabalho a pé, revelam ser irrelevantes quando da fixação do Normbereich pelo intérprete autêntico, quando este é provocado a apreciar questões relativas ao descumprimento de normas de ergonomia, ainda que tenha relação com a vida laboral cotidiana do trabalhador.

Uma vez estabelecido o âmbito da norma, obtido no nono passo no processo de concretização, e o programa da norma, firmado na etapa anterior, tem-se $\overline{{ }^{50} \text { Ibidem, 2010, p. } 98 .}$

${ }^{51}$ CHRISTENSEN, Ralph. Teoria estruturante do direito. In: MÜLLER, Friedrich. O novo paradigma do direito: introdução à teoria e metódica estruturantes do direito. 3. ed. São Paulo: Revista dos Tribunais, 2013, p. 207.

${ }^{52}$ ADEODATO, João Maurício. Norma jurídica como decisão dotada de efetividade. Revista Jurídica da Presidência, Brasília, v. 15, n. 106, p. 313, jun./set. 2013. 
constituída a denominada estrutura da norma ${ }^{53}$ ou Rechtsnorm. Essa etapa do procedimento de concretização refere-se ao momento de correlação da situação fática do caso concreto apresentado ao órgão julgador ao texto da norma positivada.

Utilizando-se da sistemática anteriormente escolhida para a visualização das etapas do processo de concretização, por meio de exemplos ligados à segurança e à medicina do trabalho, tem-se que o empregador, ao não fornecer os protetores auriculares aos empregados que laboram na atividade de montagem de equipamentos com furadeiras, ou que não fornece luvas químicas para a proteção na atividade com óleos e graxas, descumpre a norma de segurança e medicina do trabalho, prevista na Norma Regulamentadora ${ }^{0} 15$ do Ministério do Trabalho e na Constituição da República.

A partir da construção da norma jurídica propriamente dita, que leva em conta todos os elementos do caso concreto, chega-se a elaboração da norma decisória ou Entscheidungsnorm. A norma de decisão é, portanto, a representação da consequência jurídica que decorre da norma jurídica abstratamente considerada.

No exemplo anteriormente apresentado, o empregador, ao deixar de fornecer o equipamento de segurança ao trabalhador para neutralizar os agentes insalubres, além de incorrer em infração administrativa, tem a obrigação de efetuar o pagamento do adicional de insalubridade.

O momento da concretização somente é finalizado na metódica estruturante, segundo magistério de Eros Roberto Grau ${ }^{54}$, a partir da confecção do comando decisório ou da norma decisória. Esta, portanto, constitui a aplicação no âmbito prático da norma do direito positivado ao caso posto a julgamento.

\section{A LEGITIMIDADE DA ATUAÇÃO JURISDICIONAL NA CRIAÇÃO DA NORMA JURÍDICA NO ESTADO DEMOCRÁTICO DE DIREITO}

A teoria estruturante da norma desenvolvida por Friedrich Müller tem o papel de consolidar a distinção já há muito presente no cenário do pós-positivismo jurídico entre o texto normativo e a norma jurídica propriamente dita. Acerca desta

\footnotetext{
53 JOUANJAN, Olivier. De Hans Kelsen a Friedrich Müller: método jurídico sob o paradigma pós-positivista. In: MÜLLER, Friedrich. O novo paradigma do direito: introdução à teoria e metódica estruturantes do direito. 3 . ed. São Paulo: Revista dos Tribunais, 2013, p. 213.

${ }^{54}$ GRAU, Eros Roberto. Por que tenho medo dos juízes?: a interpretação/aplicação do direito e os princípios. 6. ed. São Paulo: Malheiros, 2013, p. 33.
} 
distinção, Canotilho ${ }^{55}$ destaca que o texto de lei funciona como representação de um signo linguístico, ou seja, o dado de entrada da atividade hermenêutica empreendida pelo operador do direito, ao passo que a norma jurídica representa o produto da interpretação do texto normativo.

A exposição na seção anterior dos 11 momentos dinâmicos na sistemática de concretização da norma jurídica deixa evidente que as bases do juspositivismo não foram totalmente abandonadas, como se observa na obrigatoriedade do intérprete partir em sua atividade dos elementos linguísticos contidos no texto legal. $\mathrm{O}$ texto de lei representa o ponto de partida que deve ser observado pelo julgador.

A observância do texto de lei imprime à metódica estruturante da norma a segurança jurídica exigida no paradigma atual do Estado de direito Democrático, evitando as discricionariedades e as arbitrariedades judiciais. Friedrich Müller ${ }^{56}$ adverte em sua teoria que "o texto da norma não é aqui nenhum elemento conceitual da norma jurídica, mas o dado de entrada/input mais importante do processo de concretização, ao lado do caso a ser decidido juridicamente".

Os elementos linguísticos do texto da norma, por funcionarem como balizas interpretativas, constituem instrumentos garantidores da segurança do próprio jurisdicionado, destinatário da atividade hermenêutica realizada pelo Poder Judiciário.

O controle do processo decisório garante o desvelamento das razões racionais que levaram à formação do convencimento do intérprete autêntico, assegurando a possibilidade de discussão das premissas de julgamento e, consequentemente, efetivando as garantias constitucionais da ampla defesa e do contraditório. A possibilidade de controle mediante o restabelecimento do caminhar interpretativo garante a legitimidade do processo decisório, pedra angular no Estado democrático de Direito.

A possibilidade de os órgãos judiciais superiores reconstruir o caminho trilhado pelo órgão julgador de instância anterior das etapas do processo de construção da norma jurídica certifica a legitimidade necessária da atividade do Poder Judiciário ${ }^{57}$. É afastada assim a compreensão de legitimidade meramente formal das decisões judiciais do modelo do positivismo normativista, decorrente da simples observância da dicção da lei, esta confundida com a própria norma jurídica.

\footnotetext{
${ }_{55}$ CANOTILHO, José Joaquim Gomes. Direito constitucional e teoria da constituição. 7. ed. Coimbra: Almedina, 2011, p. 1217.

${ }^{56}$ MÜLLER, Friedrich. O novo paradigma do direito: introdução à teoria e metódica estruturantes do direito. 3 . ed. São Paulo: Revista dos Tribunais, 2013, p. 99.

${ }^{57}$ CHRISTENSEN, Ralph. Teoria estruturante do direito. In: MÜLLER, Friedrich. O novo paradigma do direito: introdução à teoria e metódica estruturantes do direito. 3. ed. São Paulo: Revista dos Tribunais, 2013, p. 204.
} 
A legitimidade judicial passa a ser aferida no modelo da metódica estruturante desenvolvida na seção anterior a partir de aspectos materiais, ou seja, na possibilidade do destinatário da aplicação da norma conhecer as etapas cognoscitivas pelas quais passou o magistrado na solução do caso concreto.

A grande inovação da teoria estruturante do direito, e nisso se distingue das teorias do positivismo jurídico, está relacionada à admissão de elementos ou circunstâncias do caso concreto na atividade de criação da norma jurídica. Direito e realidade manifestam mútua influência ${ }^{58}$, superando a dicotomia entre as esferas do "ser" e do "dever-ser".

Ao não ser concebida a norma jurídica a priori, já que os elementos da realidade são integrantes da atividade de sua construção, garante-se que as decisões judiciais são tomadas apenas diante do caso concreto apresentado ao julgador. É efetivado, a partir da teoria estruturante da norma, o direito fundamental do jurisdicionado a uma decisão judicial devidamente fundamentada em elementos fáticos e jurídicos, bem como são atendidos os princípios fundamentais da legalidade e da separação dos poderes.

\section{CONSIDERAÇÕES FINAIS}

O paradigma do pós-positivismo jurídico tem a centralidade da Constituição e a força normativa dos seus princípios estruturantes como base central no processo de interpretação e de construção do direito.

A abertura do processo hermenêutico, a partir de uma leitura dos princípios constitucionais fundamentais, propiciou o desenvolvimento da teoria estruturante do direito, que representa a manifestação concreta do processo de construção da norma jurídica. A compreensão da norma jurídica como sinônimo de texto de lei do paradigma de Estado liberal de Direito tornou-se obsoleta em razão da natureza metaindividual dos conflitos da sociedade da pós-modernidade, que passou a exigir dos intérpretes autênticos uma leitura do direito positivo à luz dos fatos sociais que lhe são apresentados.

O modelo de decisão judicial do modelo liberal foi cunhado para garantir a segurança jurídica e a estabilização das relações sociais. A legitimidade do processo

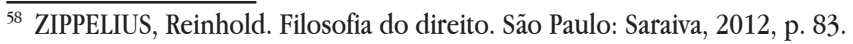


decisório decorre da compreensão de que o órgão julgador deve estar adstrito à aplicação da lei ao caso concreto. A aferição dos fatos sociais que devem ser regulados pelo direito é realizada durante o processo de elaboração legislativa pelos representantes do povo.

A massificação dos conflitos da sociedade globalizada passou a exigir do hermeneuta a integração do direito com o fato social, seja pela impossibilidade do órgão legislador em prever todas as situações de possível regulamentação ou mesmo pelas peculiaridades que cada caso concreto apresenta. Não obstante a abertura interpretativa atribuída pelo pós-positivismo jurídico, o ideal de segurança jurídica é mantido, o que confere a legitimidade ao processo decisório empreendido pelos intérpretes autênticos.

A teoria estruturante do direito, concebida no realismo jurídico, permite estabelecer por etapas o processo de construção da norma a partir dos contornos estabelecidos pelo seu texto. A possibilidade de reconstrução do caminho decisório na formulação da norma jurídica garante ao Poder Judiciário, ainda que seus membros não sejam eleitos pelo povo, a legitimação social necessária para que as decisões sejam cumpridas.

\section{REFERÊNCIAS}

ADEODATO, João Maurício. Ética e retórica: para uma teoria da dogmática jurídica. São Paulo: Saraiva, 2002.

ADEODATO, João Maurício. Norma jurídica como decisão dotada de efetividade. Revista Jurídica da Presidência, Brasília, v. 15, n. 106, p. 307-335, jun./set. 2013.

BARROSO, Luís Roberto. Neoconstitucionalismo e constitucionalização do direito. Boletim de direito administrativo, São Paulo, ano 23, n. 1, jan. 2007.

CANOTILHO, José Joaquim Gomes. Direito constitucional e teoria da constituição. 7. ed. Coimbra: Almedina, 2011.

CHRISTENSEN, Ralph. Teoria estruturante do direito. In: MÜLLER, Friedrich. O novo paradigma do direito: introdução à teoria e metódica estruturantes do direito. 3. ed. São Paulo: Revista dos Tribunais, 2013. 
COLEMAN, Jules. The practice of principle: in defence of a pragmatist approach to legal theory. New York: Oxford, 2003.

CONTE, Christiany Pegorari. A aplicabilidade da teoria estruturante no direito contemporâneo face à crise do positivismo clássico. In: CONGRESSO NACIONAL DO CONPEDI, 17., 2008. Anais... Brasília, 2008. Disponível em: http://www.conpedi. org.br/anais_brasilia.html.

DWORKIN, Ronald. Law's empire. Cambridge: Harvard University Press, 1986.

FERNANDES, Ricardo Vieira de Carvalho; BICALHO, Guilherme Pereira Dolabella. Do positivismo ao pós-positivismo jurídico. Revista de informação legislativa, Brasília, ano 48, n. 189, p. 105-131, jan./mar. 2011.

GRAU, Eros Roberto. Por que tenho medo dos juízes?: a interpretação/aplicação do direito e os princípios. 6. ed. São Paulo: Malheiros, 2013.

JOUANJAN, Olivier. De Hans Kelsen a Friedrich Müller: método jurídico sob o paradigma pós-positivista. In: MÜLLER, Friedrich. O novo paradigma do direito: introdução à teoria e metódica estruturantes do direito. 3. ed. São Paulo: Revista dos Tribunais, 2013.

KELSEN, Hans. Teoria pura do direito. Tradução de João Baptista Machado. 6. ed. São Paulo: Martins Fontes, 1998.

KIM, Richard Pae. Neoconstitucionalismo: hermenêutica constitucional e atividade jurisdicional na tutela dos direitos do cidadão. Revista da Ajuris, Porto Alegre, ano XXXVI, n. 116, p. 272, dez. 2009.

MASCARO, Alysson Leandro. Filosofia do Direito. 2. ed. São Paulo: Atlas, 2012.

MAXIMILIANO, Carlos. Hermenêutica e aplicação do direito. 20. ed. Rio de Janeiro: Forense, 2013.

MÜLLER, Friedrich. Metodologia do direito constitucional. 4. ed. rev. atual. e ampl. São Paulo: Revista dos Tribunais, 2010. 
MÜLLER, Friedrich. O novo paradigma do direito: introdução à teoria e metódica estruturantes do direito. 3. ed. São Paulo: Revista dos Tribunais, 2013.

MÜLLER, Friedrich. Teoria estruturante do direito. 3. ed. rev. atual. São Paulo: Revista dos Tribunais, 2011.

MÜLLER, Friedrich. Teses sobre a estrutura das normas jurídicas. Revista dos Tribunais, São Paulo, ano 102, vol. 929, p.193-209, mar. 2013.

NIGRO, Rachel. A virada linguístico-pragmática e o pós-positivismo. Revista Direito, Estado e Sociedade, Rio de Janeiro, n. 34, p.170-211, jan./jun. 2009.

PERLINGIERI, Pietro. Perfis do direito civil: introdução ao direito civil constitucional. 2. ed. Rio de Janeiro: Renovar, 2002.

POZZOLO, Susanna. Un constitucionalismo ambiguo. In: CARBONELL, Miguel (Org.). Neoconstitucionalismo(s). 4. ed. Madri: Trota, 2009.

STRECK, Lênio Luiz. O (pós-) positivismo e os propalados modelos de juiz (Hércules, Júpiter e Hermes): dois decálogos necessários. Revista de Direitos e Garantias Fundamentais, Vitória, n. 7, p.15-45, jan./jun. 2010.

SUNDFELD, Carlos Ari. Fundamentos de direito público. 4. ed. São Paulo: Malheiros, 2009.

ZIPPELIUS, Reinhold. Filosofia do direito. São Paulo: Saraiva, 2012.

Recebido em: 01 de janeiro de 2017 Aceito em: 21 de março de 2018 